\title{
Instructional factors and over-education of university graduates over time
}

\author{
V. González-Romá ${ }^{1,2}$, A. Hernández ${ }^{1,2}$, J.P. Gamboa ${ }^{2}$ \\ IDOCAL $^{1}$, OPAL ${ }^{2}$, University of Valencia
}

\begin{abstract}
The aim of this study is to test the role of the level of generic competences developed during University studies and the professional and practice orientation of instruction (PPOI) in the prediction of graduates' initial vertical fit and change in vertical fit over an 8-year period. The study sample comprised 334 graduates who finished their degrees two years before they were interviewed for the first time (Time 1). Four and eight years later they were interviewed again (Times 2 and 3, respectively). All of them were employed at Times 1, 2 and 3. Hypotheses were tested by means of Latent Growth Curve Analysis. The results showed that only PPOI was positively and significantly related to graduates' rate of change in vertical fit over time, meaning that the rate of change of graduates who received a more professional and practice-oriented instruction was faster than the rate of change of graduates who received a less professional and practice-oriented instruction.
\end{abstract}

Keywords: generic competences; professional orientation of instruction; vertical fit; over-education

\section{Introduction}

Over-education is an important issue among Spanish graduates (García-Montalvo \& Peiró, 2009). It means that many graduates have jobs that require lower educational levels than the level they actually have.

Taking into account the negative consequences of over-education (i.e. it has been negatively related to salaries, job and life satisfaction, well-being, etc.) (McKee-Ryan \& Harvey, 2011), it is important to know what kinds of factors prevent young people from starting their professional careers as over-educated employees and/or mitigate this situation over time. In the context of Higher Education Institutions, some instructional factors may be especially relevant because they could become routes to prevent graduates' over-education and reduce it over time. There is some evidence that the quality of training and the orientation of teaching toward labour market demands have a positive effect on educational fit (Verhaest \& van der Velden, 2013). However, empirical evidence in this area is still quite scarce.

With this in mind, we expect that teaching focused on the development of key job competences and abilities, on the one hand, and instruction oriented toward professional practice (PPOI), on the other, will allow graduates to obtain jobs that fit their educational levels better. Thus, we propose the following hypotheses:

Hypothesis 1: Higher levels of generic competences acquired during university studies will be positively related to initial levels of graduates' vertical fit and its rate of change over an 8-year period.

Hypothesis 2: Professional and practice orientation of instruction (PPOI) will be positively related to initial levels of graduates' vertical fit and its rate of change over an 8-year period. 


\section{Method}

\section{Sample and procedure}

To test the study hypotheses, we used longitudinal data from a representative sample of university graduates who obtained their degrees in 2002 and 2003. The sample was surveyed two (Time 1), six (Time 2) and ten years after graduation (Time 3). The final sample comprised 334 graduates who were employed at Times 1, 2 and 3 . The average age of respondents was $27.4(\mathrm{SD}=4.3)$ at Time 1 . Regarding sex, $63.8 \%$ were female. In terms of their fields of study, respondents were distributed as follows: Engineering (6\%), Natural Sciences and Mathematics (11.4\%), Humanities (13.2\%), Health Sciences (17.4\%), Educational Sciences (18.9\%), and Social Sciences (33.2\%).

\section{Measures}

To measure the study variables, we used a number of scales and items included in the questionnaire administered to the surveyed graduates.

Development of generic competences at Time 1 was assessed by the following question with 9 items, "To what extent has the training received at the university contributed to the development of each of the following competences and abilities?: 1. social skills, 2. time and resources planning and management, 3. problem solving, 4. decision making, 5. creativity, 6. management, 7. team work, 8. critical thinking, 9. oral and written communication. Respondents answered by using a response scale that ranged from 0 (It has not contributed at all) to 10 (It has contributed a lot).

A global competence score was calculated by averaging the ratings provided for the nine competences mentioned above. The scale reliability (Cronbach's coefficient alpha $=.91$ ) was satisfactory.

Professional and practice orientation of instruction (PPOI). This variable was measured at Time 1 by means of a 4-item scale (e.g., "Teaching methods facilitate the acquisition of professional abilities and skills"). The response scale ranged from 0 (strongly disagree) to 10 (strongly agree). The scale reliability (Cronbach's coefficient alpha $=.81$ ) was satisfactory.

Vertical fit. The dependent variable was operationalized as the ratio between the educational level required by the job and the graduate's attained educational level. Graduates were asked to indicate the educational level required by their current job. The response options were as follows: 1 . None, 2. Compulsory education, 3. Vocational education-1st level, 4. Vocational education-2nd level, 5. High school, 6. A 3-year university degree, and 7. A 5-year university degree. Graduates' attained educational level only presented two values (6. A 3-year university degree or 7. A 5-year university degree). Therefore, values less than one $(<1)$ indicate over-education (graduate has a higher level of studies than what is required by the job). Values equalling one (1) indicate vertical fit. Graduates’ vertical fit was calculated at T1, T2 and T3.

\section{Analysis}

We tested our hypotheses by means of Latent Growth Curve Analysis. The analyses were conducted with MPlus using Maximum Likelihood estimation methods. Apart from our two independent variables (competences acquired and PPOI), we controlled for a number of variables: academic performance (average degree mark), sex, age, social class, and field of study (basic, technical, health, social, humanities, and educational sciences). For the field of study, 5 dummy variables were created, using 
humanities as the reference category. All the variables were introduced as predictors of initial vertical-fit (intercepts) and fit change over time (slopes).

\section{Results and Discussion}

Regarding our hypotheses, the tested model was satisfactory in terms of fit $\left(\chi^{2}=24.06\right.$, $\mathrm{df}=13 ; \mathrm{p}<.05$; RMSEA=.05; CFI=.96; TLI=.89; SRMSR=.02). The results are shown in Tables 1 and 2. The professional and practice orientation of the instruction received at the University was positively and significantly related to graduates' rate of change in vertical fit over time (estimate $=.01$; standardized estimate $=.25 \mathrm{p}<.05$ ). In other words, the rate of positive change toward better fitting jobs in graduates who received a more professional and practice-oriented instruction was faster than the rate of change in graduates who received a less professional and practice-oriented instruction. Contrary to our expectations, the level of competence developed during the studies did not significantly predict the initial levels of vertical fit or the rate of change in fit.

Table 1. Results of the Latent Growth Curve Analysis to estimate the relationship between the predictors and graduates' initial vertical fit

\begin{tabular}{|c|c|c|c|}
\hline & Estimate & $\mathrm{SE}$ & $\mathrm{p}^{\mathrm{b}}$ \\
\hline Age & -0.007 & 0.003 & 0.017 \\
\hline Sex & 0.028 & 0.026 & 0.291 \\
\hline Social class & 0.016 & 0.009 & 0.077 \\
\hline Average mark & 0.019 & 0.030 & 0.516 \\
\hline Dummy Basics & 0.013 & 0.048 & 0.788 \\
\hline Dummy Technical & 0.045 & 0.060 & 0.452 \\
\hline Dummy Social & -0.020 & 0.039 & 0.603 \\
\hline Dummy Education & -0.029 & 0.043 & 0.496 \\
\hline Dummy Health & 0.079 & 0.043 & 0.068 \\
\hline Competences development $^{\text {Dem }}$ & 0.006 & 0.010 & 0.516 \\
\hline PPOI & -0.008 & 0.009 & 0.363 \\
\hline
\end{tabular}

${ }^{\text {a }}$ Professional and Practice Orientation Instruction

b Unstandardized Coefficients. Two-tail p-values

Table 2. Results of the Latent Growth Curve Analysis to estimate the relationship between the predictors and the rate of change in vertical fit over time

\begin{tabular}{|c|c|c|c|}
\hline & Estimate & $\mathrm{SE}$ & $\mathrm{p}^{\mathrm{b}}$ \\
\hline Age & -0.001 & 0.002 & 0.452 \\
\hline Sex & 0.014 & 0.015 & 0.355 \\
\hline Social class & 0.004 & 0.005 & 0.398 \\
\hline Average mark & 0.005 & 0.017 & 0.742 \\
\hline Dummy Basics & 0.002 & 0.027 & 0.941 \\
\hline Dummy Technical & -0.023 & 0.034 & 0.491 \\
\hline Dummy Social & 0.010 & 0.022 & 0.637 \\
\hline Dummy Education & 0.033 & 0.024 & 0.168 \\
\hline Dummy Health & -0.005 & 0.024 & 0.849 \\
\hline Competences development $^{\text {PPOI }}$ & 0.002 & 0.005 & 0.731 \\
\hline Pomp & 0.010 & 0.005 & 0.046 \\
\hline
\end{tabular}

\footnotetext{
${ }^{a}$ Professional and Practice Orientation Instruction
}

${ }^{\mathrm{b}}$ Unstandardized Coefficients. Two-tail p-values 


\section{Conclusions}

The results show that universities should consider increasing the professional and practice orientation of the instruction (PPOI) they provide because it may help to reduce graduates' over-education over time. This could be mainly due to the fact that PPOI can affect graduates' job search process. Specifically, PPOI can give graduates a broader knowledge of the labour market, which, in turn, can help them to avoid experiencing career indecision (Zikic \& Hall, 2009) and ending up in mismatched jobs.

In addition, an education oriented toward professional practice, which clearly shows professional paths and relates theory to practice, is likely to be a facilitator of career exploration, and this may also contribute to improving fit over time (Zikic \& Hall, 2009). Finally, a professionally oriented education can also contribute to higher job search clarity in graduates, which has shown positive effects on job search intensity and outcomes (Côté, Saks \& Zikic, 2006).

\section{References}

Boudarbat, B., \& Chernoff, V. (2010). The Determinants of Education-Job Match among Canadian University Graduates. Scientific Series, 2010s-14. Montreal: Cirano.

Côté, S., Saks, A. M., \& Zikic, J. (2006). Trait affect and job search outcomes. Journal of Vocational Behavior, 68, 233-252.

Feldman, D.C. (1996). The nature, antecedents, and consequences of underemployment. Journal of Management, 22, 385-407.

Grayson, J.P. (2004). Social dynamics, university experiences, and graduates' job outcomes. British Journal of Sociology of Education, 25, 609-627.

García-Montalvo, J., \& Peiró, J.M. (2009). Análisis de la sobrecualificación y de la flexibilidad laboral. Observatorio de Inserción Laboral de los Jóvenes 2008. Valencia: Fundación Bancaja-IVIE.

Kanfer, R., Wanberg, C. R., \& Kantrowitz, T. M. (2001). Job search and employment: A personality-motivational analysis and meta-analytic review. Journal of Applied Psychology, 86, 837-855.

McKee-Ryan, F. M., \& Harvey, J. (2011). “I Have a Job, But...”: A Review of Underemployment. Journal of Management, 37, 962-996.

Saks, A.M., \& Ashforth, B.E. (2002). Is Job Search Related to Employment Quality? It All Depends on the Fit. Journal of Applied Psychology, 87, 646-654.

Valls, V., González-Romá, V. Hernández, A., Yeves, J., \& Gamboa, J.P. (2013) Quality of Education and New Entrants' Job Search Intensity: The Mediating Role of General Self-efficacy. 16th EAWOP congress. Munster (Germany).

Verhaest, D., \& van der Velden, R. (2013). Cross-country Differences in Graduate Overeducation. European Sociological Review, 29, 642-653.

Zikic, J., \& Hall, D.T. (2009). Toward a More Complex View of Career Exploration. The Career Development Quarterly, 58, 181-191. 